\title{
Changes in brain catecholamine levels in human cirrhotic hepatic encephalopathy
}

\author{
G CUILLERET, G POMIER-LAYRARGUES, F PONS, J CADILHAC, \\ AND H MICHEL \\ From the Clinique des Maladies de l'Appareil Digestif, Hôpital St-Eloi, Montpellier, and Laboratoire \\ de Pathologie et de Therapeutique Générales, Faculty of Medicine, Montpellier, France
}

SUMMARY Hepatic encephalopathy (HE) is currently felt to be secondary to a disturbance in the metabolism of cerebral catecholamines with a decline in dopamine and noradrenaline and a rise in the false neurotransmitter octopamine. The aim of this study was to evaluate brain tissue levels of dopamine, noradrenaline, and octopamine in patients with cirrhosis and HE. This study includes 34 patients: 22 were cirrhotic, 12 were control subjects. Among the 22 cirrhotic patients, 19 had HE, three did not. Tissue specimens were obtained at necropsy from the locus niger, caudate nucleus, hypothalamus, thalamus and frontal cortex, and from the frontal cortex during neurosurgical procedures. Our results showed that (1) dopamine and noradrenaline levels are identical in cirrhotic patients with or without $\mathrm{HE}$ and in patients without liver disease $(\mathrm{P}<0.05)$; (2) octopamine levels are higher in control subjects than in patients with cirrhosis and HE. In conclusion, there is no decline in dopamine and noradrenaline levels in the brain tissues of cirrhotic patients with $\mathrm{HE}$, and this is in contradication with the animal findings; octopamine levels are not raised. Hepatic encephalopathy in human liver cirrhosis does not seem to be secondary to a disturbance in cerebral catecholamines.

At present some authors ${ }^{1}$ think that hepatic encephalopathy (HE) is caused by an impairment in the metabolism of brain catecholamines. In normal subjects, catecholamines (dopamine and noradrenaline) carry nerve impulses across central and peripheral synapses. $^{2}$ In contrast, during hepatic encephalopathy, resulting from an acute or chronic hepatic injury, the neurological manifestations could result from an accumulation of false neurotransmitters in synapses, substituting for dopamine and noradrenaline. ${ }^{1}$ Octopamine is thought to be the main false neurotransmitter. ${ }^{3}$

The purpose of this study is to measure brain catecholamine and octopamine levels in cirrhotic patients, with and without hepatic encephalopathy and compare these results with those found in normal control subjects.

\section{Methods}

PATIENTS

Studies were carried out on the following two groups:

Received for publication 22 January 1980

\section{Group 1}

This consisted of 22 cirrhotic patients, 19 of whom were in stage III of $\mathrm{HE}$ - that is, in deep coma-and three had no evidence of $\mathrm{HE}$. The diagnosis was based on laparoscopy, liver biopsy, and/or necropsy findings, biochemical liver tests, and EEG.

Among the 19 cirrhotic patients with $\mathrm{HE}, 15$ received lactulose enemas and either neomycin ( $2 \mathrm{~g} /$ day) or tetracycline $(1.5 \mathrm{~g} /$ day $)$; only four received $\mathrm{L}$ dopa ( $4 \mathrm{~g} /$ day). All of the $\mathrm{HE}$ cirrhotic patients died from hepatic failure and the three cirrhotic patients without hepatic encephalopathy died from gastrointestinal cancers without liver metastases.

\section{Group 2}

This consisted of 12 control subjects, without evidence of liver disease as assessed either by biochemical liver tests (four patients) or liver biopsy (eight patients). Among these controls, eight patients died. The causes of death were gastrointestinal cancer in three patients, cancer of the kidney (one), ventricular fibrillation (one), acute 
pancreatitis (one), peritonitis (one), and pulmonary embolism (one).

\section{BRA IN SAMPLES}

In 30 patients, brain samples were taken postmortem in several areas of the brain. In the four remaining patients (controls), brain cortex biopsies were obtained neurosurgically. In these cases, obviously, samples in other brain structures would have been impossible.

Samples for dopamine and noradrenaline assays were taken in cerebral dopaminergic structures (substantia nigra, caudate nucleus, putamen) and noradrenergic structures (hypothalamus, thalamus, and frontal cortex). ${ }^{24}$ Octopamine levels were determined on frontal cortex samples in the four neurosurgical controls and in four HE cirrhotic patients. Post-mortem samples were stored within an average of two hours 45 minutes after death (ranging from one hour 30 minutes to six hours 30 minutes). Moreover, serial brain samples for dopamine and noradrenaline determinations were taken respectively two, four, nine, and 24 hours after death on frontal cortex and caudate nucleus at $21^{\circ} \mathrm{C}$. The average weight of the brain samples was $500 \mathrm{mg}$. Each one was wrapped in aluminium foil, then stored at $-30^{\circ} \mathrm{C}$. Catecholamine determinations were performed about three months after freezing.

\section{CATECHOLAMINE DETERMINATIONS}

Dopamine levels were determined by the fluorometric method of Carlsson and Waldeck..$^{5}$ Noradrenaline was measured by the fluorometric method of Bertler et al., ${ }^{6}$ and octopamine by the enzymatic and radioisotopic method of Molinoff et al. ${ }^{7}$ Results are presented in $\mathrm{ng} / \mathrm{g}$ of brain tissue.

\section{STATISTICAL CALCULATIONS}

We compared dopamine and noradrenaline levels between (1) controls and cirrhotic patients with HE not receiving $\mathrm{L}$ dopa, (2) controls and cirrhotic patients with HE receiving L dopa, (3) cirrhotic patients with HE treated with $\mathrm{L}$ dopa against those not receiving $\mathrm{L}$ dopa.

In addition, we compared octopamine levels between controls and cirrhotic patients with hepatic encephalopathy not receiving $L$ dopa.

Statistical calculations were made according to the Fisher test, using an Olivetti P 602 minicomputer, with a $95 \%$ confidence level.

\section{Results}

The following data concern brain dopamine, noradrenaline, and octopamine levels.

BRAIN DOPAMINE LEVELS (Table 1)

In control subjects, dopamine levels in the dopaminergic brain structures (substantia nigra, putamen, and caudate nucleus) are generally higher than those found in the noradrenergic brain structures (hypothalamus, thalamus, and frontal cortex). We demonstrated the same pattern in cirrhotic patients with hepatic encephalopathy.

Striking differences in dopamine concentrations were found in the substantia nigra. In this area, dopamine levels were higher in those patients with HE who were not receiving $L$ dopa compared with the control group. In contrast, dopamine levels in the putamen, caudate nucleus, hypothalamus, thalamus, and frontal cortex were not statistically different in controls and cirrhotic patients whether they were receiving L dopa or not. Dopamine levels were the same in cirrhotic patients treated and not treated with $\mathrm{L}$ dopa.

Moreover, in two cirrhotic patients with HE and one control, brain dopamine levels remained unchanged when sampled two, four, nine, and 24 hours after death (Table 4).

BRAIN NORADRENALINE LEVELS (Table 2)

In control subjects, noradrenaline levels were the same in the substantia nigra, putamen, and caudate nucleus (dopaminergic structure) and in the thalamus and frontal cortex (noradrenergic structures).

Table 1 Brain dopamine levels (ng/g) (mean $\pm S E M)$

\begin{tabular}{|c|c|c|c|c|}
\hline & \multirow[t]{2}{*}{ Control subjects } & \multicolumn{3}{|l|}{ Cirrhosis } \\
\hline & & Without $H E$ & With $H E$ & With $H E+L D O P A$ \\
\hline $\begin{array}{l}\text { Substantia nigra } \\
\text { Putamen } \\
\text { Caudate nucleus } \\
\text { Hypothalamus } \\
\text { Thalamus } \\
\text { Frontal cortex }\end{array}$ & $\begin{array}{c}394 \pm 165 *(5) \\
3127 \pm 1350 \\
2698 \pm 1555(6) \\
455 \pm 195(5) \\
187 \pm 190(6) \\
214 \pm 180(10)\end{array}$ & $\begin{array}{l}360-1424 \\
3590-3700 \\
1330-4375 \\
- \\
110-100 \\
290-1060-60\end{array}$ & $\begin{aligned} 1042 & \pm 370 *(12) \\
6385 & \pm 2752(5) \\
4774 & \pm 1159(11) \\
503 & \pm 175(11) \\
386 & \pm 27(12) \\
158 & \pm 70(14)\end{aligned}$ & $\begin{array}{l}442 \pm 253(4) \\
- \\
5770-3150 \\
602 \pm 443(4) \\
174 \pm 70(4) \\
312 \pm 211(4)\end{array}$ \\
\hline
\end{tabular}

*P $<0.05$

Number of patients in parentheses. 
Table 2 Brain noradrenaline levels $(n g / g)($ mean $\pm S E M)$

\begin{tabular}{|c|c|c|c|c|}
\hline & \multirow[t]{2}{*}{ Control subjects } & \multicolumn{3}{|l|}{ Cirrhosis } \\
\hline & & Without $H E$ & With $H E$ & With $H E+\mathrm{L} D O P A$ \\
\hline $\begin{array}{l}\text { Substantia nigra } \\
\text { Putamen } \\
\text { Caudate nucleus } \\
\text { Hypothalamus } \\
\text { Thalamus } \\
\text { Frontal cortex }\end{array}$ & $\begin{array}{c}136 \pm 140(6) \\
40-0 \\
92 \pm 63(6) \\
746 \pm 275(5) \\
188 \pm 126(6) \\
55 \pm 34(10)\end{array}$ & $\begin{array}{l}60-385 \\
40-125 \\
40-147 \\
-80-96 \\
8-284-147\end{array}$ & $\begin{array}{c}262 \pm 88(12) \\
255 \pm 134(5) \\
154 \pm 98(12) \\
792 \pm 348(11) \\
197 \pm 47(12) \\
83 \pm 28(15)\end{array}$ & $\begin{array}{c}204 \pm 193(4) \\
\overline{228} \pm 152(4) \\
571 \pm 408(4) \\
200 \pm 65(4) \\
97 \pm 92(4)\end{array}$ \\
\hline
\end{tabular}

Number of patients in parentheses.

However, the noradrenaline concentration was higher in the hypothalamus.

In the cirrhotic patients with $\mathrm{HE}$, noradrenaline levels in the substantia nigra, putamen, and caudate nucleus were the same as those found in the thalamus and frontal cortex (Table 3). Here again, the noradrenaline levels were higher in the hypothalamus.

Nevertheless, we found no significant differences in the brain noradrenaline concentrations between control subjects and cirrhotic patients with HE who were either treated or not treated with $\mathbf{L}$ dopa; this was true for the six brain areas studied. In addition, brain noradrenaline levels were the same in cirrhotic patients with $\mathrm{HE}$ who were treated or not treated with $\mathbf{L}$ dopa.

Moreover, in two cirrhotic patients with HE and one control, brain noradrenaline levels remained unchanged when sampling two, four, nine, and 24 hours after death (Table 4).

BRAIN OCTOPAMINE LEVELS (Table 3)

Brain cortex octopamine levels were significantly higher in living controls than in dead cirrhotic patients with hepatic encephalopathy.

\section{Discussion}

Three points must be considered: the appropriateness of brain catecholamine determinations, the accuracy of the data, and the false neurotransmitter theory.

BRAIN CATECHOLAMINE DETERMINATIONS Dopamine, noradrenaline, and octopamine determinations in each brain structure are a more direct evaluation of cerebral aminergic activity than urinary determinations of catabolites such as

Table 3 Brain octopamine levels $(\mathrm{ng} / \mathrm{g})($ mean $\pm S E M)$

\begin{tabular}{lll}
\hline & Control subjects & Cirrhosis with HE \\
\hline Frontal cortex & $59 \cdot 2 \pm 13 \cdot 3(5) *$ & $36 \pm 6 \cdot 1(4)$ \\
\hline $\begin{array}{l}\mathrm{P}<0.01 . \\
\text { Numbers of patients in parentheses. }\end{array}$ &
\end{tabular}

homovanilic acid (HVA) for dopamine, and 3 methoxy 4 hydroxy phenyl glycol for noradrenaline.

Measurement of the concentrations of these metabolites does not accurately reflect brain catecholamine levels. Obviously, brain samples can only be taken post-mortem, as in vivo biopsies are not justifiable in cirrhotic patients with hepatic encephalopathy. Even so, only cerebral cortex samples could be obtained.

On the other hand, the reason for the dopamine increase in the substantia nigra of the cirrhotic patients with $\mathrm{HE}$ as compared with control values remains obscure.

\section{ACCURACY OF DATA}

Brain catecholamine levels could conceivably be modified by the time lapse between death and the freezing of the brain samples. In both the rat, ${ }^{8}$

Table 4 Modifications of cerebral catecholamines (ng/g) related to delay between sample freezing and death

\begin{tabular}{|c|c|c|c|c|c|}
\hline & \multicolumn{5}{|c|}{ Delay post mortem (h) } \\
\hline & 2 & 4 & 9 & 24 & \\
\hline \multicolumn{6}{|c|}{$\begin{array}{l}\text { Frontal cortex } \\
\text { Patient no. }\end{array}$} \\
\hline 1 & 70 & 100 & 70 & - & \\
\hline 2 & 500 & 100 & 333 & 366 & NS \\
\hline 3 & 97 & 97 & 313 & 97 & \\
\hline \multicolumn{6}{|c|}{ Caudate nucleus } \\
\hline 1 & 1570 & 1630 & 2260 & - & \\
\hline 2 & 5899 & 6666 & 5000 & 5266 & NS \\
\hline 3 & 2268 & 1609 & 1830 & 2268 & \\
\hline \multicolumn{6}{|c|}{$\begin{array}{l}\text { Noradrenaline } \\
\text { Frontal cortex }\end{array}$} \\
\hline 1 & 60 & 48 & 36 & - & \\
\hline 2 & 41 & 55 & 27 & 55 & \\
\hline \multirow{2}{*}{\multicolumn{6}{|c|}{$\begin{array}{l}\text { Caudate nucleus } \\
\text { Patient no. }\end{array}$}} \\
\hline & & & 48 & - & \\
\hline 2 & 148 & 227 & $\begin{array}{r}40 \\
148\end{array}$ & $\overline{125}$ & $\mathbf{N S}$ \\
\hline 3 & 88 & 60 & 30 & 88 & \\
\hline
\end{tabular}

Patients no. 1 and no. 2: cirrhotic patients with HE. Patient no. 3: control. 
and man, ${ }^{9}$ brain dopamine levels decrease as this time lapse increases. However, the difference only becomes significant after six hours after death.

In our study, the delay between death and sample freezing averaged two hours $\mathbf{4 5}$ minutes for the two groups of patients (in control subjects, the average was one hour 45 minutes, in cirrhotic patients, two hours 50 minutes). Therefore, if, in fact, brain catecholamine levels had been modified by this time lapse, it would not have been significant in either group. In addition, we were able to show, in two cirrhotic patients with hepatic encephalopathy and one control, that brain catecholamine levels remained unchanged, when sampling brain at two, four, nine, and 24 hours after death. This fact could be expected, as enzymes involved in brain catecholamine metabolism remain quite stable during this period: in rats, at $21^{\circ} \mathrm{C}$, two hours after death, ${ }^{10}$ tyrosine hydroxylase and mono-aminooxydase activities fall by only $6 \%$ and $9 \%$ respectively; in contrast, during the same period, dopamine decarboxylase activity increases by $3 \%$. Lloyd et al. ${ }^{11}$ performed a similar study on patients with Parkinson's disease: in this study the delay between death and the freezing of samples varied from two to 23 hours. These authors showed that dopamine concentrations in the putamen and caudate nucleus are lower in patients with Parkinson's disease than in the control group.

\section{THEORY OF FALSE BRAIN}

\section{NEUROTRANSMITTERS}

To our knowledge, this is the first study on brain catecholamine levels in cirrhotic patients with hepatic encephalopathy. Although our findings conflict with what has already been proposed as the mechanism of both experimental ${ }^{12}$ and human cirrhotic $\mathrm{HE},{ }^{1}$ we found neither reduced dopamine and noradrenaline brain concentrations nor increased brain octopamine levels. Moreover, we found no correlation between the length of the coma and catecholamine levels in six brain areas. This argues against any effect of the duration of hepatic coma on brain catecholamine levels.

There are several other arguments that contradict this theory. For instance, in rats, intracerebral injections of high doses of octopamine did not elicit HE, ${ }^{13}$ Lal et al.$^{14}$ showed, with the probenecid test, that brain dopamine metabolism is normal in cirrhotic patients with HE. Probenecid acts to block the transfer of HVA (a final catabolite of brain dopamine) from the cerebrospinal fluid to the blood. With this test, brain dopamine metabolism can be studied by measuring the build up of HVA in the CSF. After probenecid, concentrations of HVA in the CSF rise as much in the cirrhotic patients as in the control group.

Moreover, preliminary results of our group ${ }^{15}$ demonstrate the failure of $L$ dopa treatment in hepatic encephalopathy. This is another argument, particularly in light of the known efficacy of $\mathrm{L}$ dopa in the treatment of Parkinson's disease. This is not surprising, because, in this disease, there is a significant deficiency of brain dopamine. ${ }^{11}$

\section{Conclusion}

Brain dopamine and noradrenaline levels are not found to be lower in cirrhotic patients with hepatic encephalopathy. Moreover, brain octopamine concentrations are not raised. Therefore human cirrhotic hepatic encephalopathy could not seem to be a result of a change in the metabolism of brain catecholamines.

We wish to thank Dr G Cauvet and Dr P Granier for their technical assistance; Dr R Infante, Ms M L Delorme, and Professor P Opolon for determination of brain octopamine levels; Dr P M Huet and $\operatorname{Dr} P$ Bories for reviewing the manuscript, and Mrs A Arnaud for the statistical calculations.

\section{References}

${ }^{1}$ Fischer JE, Baldessarini RJ. False neurotransmitters and hepatic failure. Lancet $1971 ; 2$ : 75-80.

${ }^{2}$ Axelrod J, Weinshilboum R. Catecholamines. $N$ Engl J Med 1972; 287: 237-42.

${ }^{3}$ Dodsworth JM, James JH, Cummings MC, Fischer JE. Depletion of brain norepinephrine in acute hepatic coma. Surgery 1974; 75: 811-20.

${ }^{4}$ Bertler $\AA$. Occurrence and localization of catecholamines in the human brain. Acta Physiol Scand 1961; 51: 97-107

${ }^{5}$ Carlsson A, Waldeck B. A fluorimetric method for the determination of dopamine (3-hydroxytyramine). Acta Physiol Scand 1958; 44: 293-8.

${ }^{6}$ Bertler $\AA$, Carlsson A, Rosengren E. A method for the fluorimetric determination of adrenaline and noradrenaline in tissues. Acta Physiol Scand 1958; 44: 273-92.

${ }^{7}$ Molinoff PB, Landsberg L, Axelrod J. An enzymatic assay for octopamine and other $\beta$ hydroxylated phenylethylamines. J Pharmacol Exp Ther 1969; 170: 253-61. ${ }^{8}$ Wiesel FA, Sedvall G. Post-mortal changes of dopamine and homovanilic acid levels in rat striatum as measured by mass fragmentography. Brain Res 1974; 65: 547-50. ${ }^{\circ}$ Carlsson $A$, Winblad $B$. Influence of age and time interval between death and autopsy on dopamine and 3-methoxytyramine levels in human basal ganglia. J Neural Transm 1976; 38: 271-6.

${ }^{10}$ Fahn S, Côté LJ. Stability of enzymes in post-morten rat brain. J Neurochem 1976; 26: 1039-42. 
${ }^{11}$ Lloyd KG, Davidson L, Hornykiewicz O. Metabolism of levodopa in the human brain. Adv Neurol 1973; 3: 173-88.

${ }^{12}$ Bloch P, Delorme ML, Rapin JR, Granger A, Boschat $M$, Opolon P. Reversible modifications of neurotransmitters of the brain in experimental acute hepatic coma. Surg Gynecol Obstet 1978; 146: 551-8.

${ }^{13}$ Zieve L, Olsen RL. Can hepatic coma be caused by a reduction of brain noradrenaline or dopamine? Gut 1977; 18: 688-91.
${ }^{14}$ Lal S, Aronoff A, Garelis E, Sourkes TL, Young SN, De La Vega CE. Cerebrospinal fluid homovanillic acid, 5-hydroxyindoleacetic acid, lactic acid, and $\mathrm{pH}$ before and after probenecid in hepatic coma. Clin Neurol Neurosurg 1974; 77: 142-52.

${ }^{15}$ Michel H, Cauvet G, Granier PM, Bali JP, Andre R, Cuilleret G. Treatment of cirrhotic hepatic encephalopathy by L-dopa. A controlled trial. Gastroenterology 1980; 79: 207-11. 